\title{
Una larga adolescencia hacia una democracia moderna. Análisis psicosocial de elecciones congresales especiales 2020
}

\author{
A long adolescence towards a modern democracy. Psychosocial analysis \\ of special congress elections 2020 \\ Víctor Eusebio Montero López ${ }^{1}$ \\ Universidad Nacional Mayor de San Marcos
}

Recibido: $07-05-20$

Aceptado: $12-06-20$

\section{Resumen}

Se analizan los resultados de las elecciones congresales especiales 2020 en términos de participación, opción de voto, así como votación preferencial; se explican los motivos psicosociales por los que se obtuvieron estos resultados y lo que constituyen en este momento los partidos políticos y sus proyecciones presidenciales y congresales 2021. Se concluye que existe fuerte cuestionamiento a la clase política, indicando muchos aspectos que nos falta en liderazgo, capacidad para gobernar y visión moderna para transformar el país.

Palabras clave: Liderazgo; democracia; clase política; motivos; preferencias.

\begin{abstract}
The results of the 2020 special congressional elections are analyzed in terms of participation, voting option, as well as preferential voting; the psychosocial reasons for which these results were obtained and what the political parties and their presidential and congressional projections 2021 are at the moment are explained. It is concluded that there is strong questioning of the political class, indicating many aspects that we lack in leadership, ability to govern and modern vision to transform the country.
\end{abstract}

Keywords: Leadership; democracy; political class; motives; preferences.

\footnotetext{
${ }^{1}$ Docente asociado de la Facultad de Psicología de la Universidad Nacional Mayor de San Marcos. Lima, Perú. E-mail: vmonterolopez@unmsm.edu.pe. ORCID: https://orcid.org/0000-0002-9968-4160

(C) Los autores. Este artículo es publicado por la Revista de Investigación en Psicología de la Facultad de Psicología, Universidad Nacional Mayor de San Marcos. Este es un artículo de acceso abierto, distribuido bajo los términos de la licencia Creative Commons Atribucion - No Comercia_Compartir Igual 4.0 Internacional. (http://creativecommons.org/licenses/by-nc-sa/4.0/) que permite el uso no comercial, distribución y reproducción en cualquier medio, siempre que la obra original sea debidamente citada.
} 
Evidentemente que las Elecciones Congresales Extraordinarias han causado varias sorpresas, pero que ni analistas ni encuestadoras pudieron darse cuenta, más aún diría no lo querían ver, como en una artículo señalé el factor ideológico no te permite reconocer algo como un problema ni detectar una realidad (Montero, 2019). Ya en otro artículo había señalado que había "una percepción negativa sobre los políticos tradicionales o más conocidos, las instituciones públicas y personajes de las mismas, y sobre los servicios de salud y educación” (Montero, 2019b), asimismo se indicó "los políticos tradicionales no tienen probabilidades de éxito electoral entre estos jóvenes, y los candidatos de anterior elección no generan confianza" y también se dijo que había una crisis de la clase política y de los partidos. $\mathrm{Y}$ esto se reflejó totalmente en esta elección, donde "la gente votó contra el sistema" (Hildebrandt, 2020) y señalé que la emoción que estaba detrás del rechazo no era el odio sino el asco y el desprecio, algo que también dice Hildebrant. Y como creer en el sistema y en el Estado si cada vez hay mayor delincuencia que aterroriza, los políticos no aprueban ninguna ley necesaria y mueren personas por explosión de gas y no hay culpables. Contexto que no hace extraño Urresti y Antauro saquen alta votación. Hildebrandt dice el problema no es que exista un Antauro sino la desilusión, parafraseando lo que dije en otro artículo (Montero, 2019b) lo que sucede no es que exista un Urresti o un Antauro sino que hay muchos Urrestis y Antauros o la mezcla de ambos. Ante la incapacidad de todo el Estado y sobre todo del Congreso, muchos desean mano dura que acabe con la corrupción, la delincuencia, el terror, los feminicidios y todo tipo de violencias y las generaciones jóvenes millennials o zetas piensan más radical aún. Llegó al máximo el hartazgo. Había una fuerte tendencia que era apoyar al que vieran respaldaba más a Vizcarra para que acabe de una vez con las reformas, y esta era votar por el Partido Morado, esto sobre todo en Lima, pero era lógico sacarían algún vídeo para cuestionar al líder, no creo por él porque como señalan los estudios mencionados no tiene chance presidencial, sino para evitar ese partido saque más congresistas. Una izquierda que no ilusionaba ni a los izquierdistas, muchos a los cuales entrevisté y me dijeron no votarían por Frente Amplio ni Juntos. Con una AP que ya decepciona en las alcaldías, lo lógico era que se polarizarán por otros radicales y allí tendencia a favor de Urresti se hizo imparable, recuerde que Lazarsfeld mencionaba que no solo hay que ver el fenómeno underwood (votar por el ganador) sino el underdog (votar por el más débil); y en el interior del país sobre todo sierra sur, el UPP se disparó en votación. Pero si bien tuvo éxito la campaña de "no votar en blanco", no se dio el hecho de que para no votar en blanco lo hicieron por FREPAP y UPP, esta decisión no era por preferir a votar en blanco, sino estos dos partidos hicieron una enorme campaña para ganarse votos y canalizaron la protesta antisistema.

Ahora qué efectos tendrán estos resultados la agenda política? Cómo pueden configurar los espacios? Qué procesos se han abierto? Elecciones anteriores han mostrado no tienen influencias en escenarios electorales posteriores, caso de la Constituyente 1978 donde no participó AP y luego llegó a la Presidencia. Los 
resultados muestran a los partidos les queda mucho trabajo por hacer. Todos los espacios del espectro político están en disputa abierta y surgirán nuevos rivales, La extrema derecha o derecha bruta y achorada ya no tiene al fujimorismo que ha sido el gran derrotado, fracasó Solidaridad como reemplazo o como "derecha popular", López puede intentar ser el "Bolsonaro peruano", pero difícil y vemos otros líderes también han fracasado. El Apra agoniza pues García lo liquidó. La derecha liberal por el centro es otro espacio en disputa. AP está en guerra interna. Partido Morado está golpeado y son también grandes perdedores y necesita mucho más para crecer y Guzmán ha mostrado grandes limitaciones. Contigo y similares ya no cuentan, APP se recicla y la plata no es todo. Mientras UPP, Frepap y Podemos son supuestos ganadores y es por su presencia nacional y su trabajo de base, pero son liderazgos autoritarios y jerárquicos. Así las redes y trabajo territorial son tan importantes como las redes sociales. Solo en 2 regiones Podemos tiene presencia. La izquierda ha retrocedido y perdió oportunidad de liderar primeros lugares y liderar las reformas, paradójico es quien más se movilizó pero no se ha traducido en reconocimiento ni votos, es consecuencia de malas decisiones, si no recomponen la coalición para generar esperanzaa, pero solo buscan imponerse y anular al otro (De Echade, 2020), como siempre lo ha hecho, a excepción con Barrantes.

Tenemos un Congreso fragmentado, con 7 bancadas, pero los resultados por regiones son interesantes. Así AP logró estar en 18 regiones, APP en 15. UPP en 13, Frepap en 12 y FA en 9, los que no están presentes en ninguna, deben entender que les falta mucho aún.

Los objetivos del estudio fueron dar a conocer los resultados sobre preferencias emitidos por las encuestadoras y sobre los resultados finales de las elecciones; comparar dichos resultados para establecer niveles de acierto o no; analizar los resultados en términos de la representación en el Congreso y proyecciones para elecciones presidenciales.

\section{MÉTODO}

Se empleó un enfoque cuantitativo en una investigación de tipo descriptiva en base a la observación, con un diseño no experimental, transversal en base a encuestas y comparación de resultados con sujetos de edades diferentes en un solo momento .

Participantes: La población de electores ha sido de 24'799,384 personas (ONPE-JNE 2020) y de allí se obtuvo una muestra en base a los electores que emitieron su voto en últimas Elecciones Congresales 2020 que son un total de votos válidos de 18’369,088, muestra que por estas características es considerada censal.

Variables: Opción por un candidato antes de elecciones. Resultado de votación.

Procedimiento: En base a los datos de Onpe (2020) se obtuvieron los datos de la población general y de la población que acudió a votar. Se elaboraron las 
tablas efectuando las sumatorias y porcentajes respectivos. Asimismo, en base a los resultados oficiales de Onpe se obtuvieron el número total de votos y el porcentaje obtenido por cada una de las agrupaciones políticas y los votos preferenciales. Igualmente, se obtuvieron las tablas de las empresas encuestadoras CPI e IPSOS en relación a preferencias, encuestas a boca de urna y resultados finales, para compararlas y analizarlas, precisando su nivel de acierto o no con los resultados finales oficiales, para el análisis y discusión de resultados. Los análisis se realizaron contrastando los datos de las encuestas y de resultados oficiales, para fines explicativos de los resultados se contrastó con resultados de investigaciones anteriores realizadas por el autor sobre líderes políticos y coyuntura nacional, así como con otras investigaciones de otros autores con fines explicativos.

\section{RESULTADOS}

Como vemos en la Tabla 1 el nivel de participación emitiendo un voto válido es de $74.07 \%$, pero un $25.93 \%$ estuvieron ausentes.

\section{Tabla 1}

Nivel porcentual de participación en elecciones 2020

\begin{tabular}{lcc}
\hline OPCIÓN DE VOTO & NÚMERO DE VOTOS & $\mathbf{\%}$ \\
\hline Total de electores hábiles & 24.799 .384 & 100,0 \\
Total de votos válidos & 18.369 .088 & 74,07 \\
Total de ausentes & 6.430 .296 & 25,93 \\
\hline
\end{tabular}

Fuente: ONPE- JNE (2020) Resultados oficiales, febrero.

Como podemos apreciar en la Tabla 2 solo hubieron 2,35\% de votos en blanco, fue mayor el número de votos nulos llegando a $17,09 \%$ y el $80.56 \%$ optó por uno de los partidos, habiendo obtenido mayor votación AP con $10.26 \%$ de votos válidos que son en realidad $8.26 \%$ del total de votos; luego le siguen dos partidos diferenciados solo por 632 votos; hay 7 partidos que superó el millón de votos válidos, ellos y el Frente Amplio y Somos Perú que casi llegan al millón de votos. El PPC logra el 3.99\% detrás de Juntos y el Apra 2,72\% ocupa el $14^{\circ}$. lugar y Solidaridad en $19^{\circ}$. lugar con $1.49 \%$ y último Contigo con $1.07 \%$

En la tabla 3, podemos ver que en Lima, la mayor votación fue para Podemos, Partido Morado y Frepap en ese orden y luego Acción Popular; y los últimos lugares fueron para Renacimiento y Contigo. Así, Lima se convirtió en el bastión de Urresti. Antauro desplazó a la izquierda en su zona fuerte. Vemos que la mayoría de candidatos con el número 1 obtuvieron la mayor votación, sin embargo esto no se cumplió en el caso de Partido Morado pues Alberto De Belaunde obtuvo 266,654 votos y Gino Costa 101,819; en Patria Segura Reggiardo también obtuvo más votos que Cilloniz, en Juntos Arbizu obtuvo más votos que el psicólogo Roberto Sánchez. Y Mejía de Avanza y del grupo "Con mi familia no te metas", 
Sheput y Heresi de Contigo, y Bartra y Vilcapoma obtuvieron bajas votaciones, En AP, APP, Perú Libre y Juntos las diferencias entre candidatos son pequeñas, en AP es solo de 24, 587 entre el primero y segundo. Y en el Apra la diferencia de Mulder con Vilchez es de 34,292 e Ibañez tuvo destacado papel pese a este ser nuevo frente a los muchos años de experiencia de Mulder y Vilchez. La mayor votación la obtuvo Urresti con 588,763, segundo De Belaunde y tercero Martha Chávez con 181,640 votos; pese a no postular obtuvieron altas votaciones Antauro Humala con 31,652 casi igual que Vega que prestó el nombre UPP e Isaac Humala 17,282 votos en Perú Libre. Comparando Tablas 2 y 3 podemos deducir que no es cierto el argumento que el voto por el Frepap es rural y del interior del país, pues este es incluso mayor en Lima que en el interior, en todo caso el Frepap canalizó los votos no solo de algunos lugares rurales pero más de sectores populares de Lima. Analizando votos por distritos se ve que sectores de clase media votaron por AP y Partido Morado.

\section{Tabla 2}

Opción de voto en número y porcentajes elecciones 2020

\begin{tabular}{|c|c|c|}
\hline OPCIÓN DE VOTO & NÚMERO DE VOTOS & $\%$ \\
\hline Total de votos emitidos & 18.369 .088 & 100,0 \\
\hline Total de votos válidos & 14.798 .379 & 80,56 \\
\hline Total de votos en blanco & 432.071 & 2,35 \\
\hline Total de votos nulos & 3.138 .638 & 17,09 \\
\hline Acción Popular & $1.518,171$ & 10,26 \\
\hline Podemos Perú & 1.240 .716 & 8,38 \\
\hline Frepap & 1.240 .084 & 8,38 \\
\hline Alianza para el Progreso & 1.178 .020 & 7,96 \\
\hline Partido Morado & 1.095 .491 & 7,40 \\
\hline Fuerza Popular & $1,081,174$ & 7.31 \\
\hline Unión por el Perú & $1,001,116$ & 6.77 \\
\hline Frente Amplio & 911,701 & 6.16 \\
\hline Somos Perú & 895,700 & 6.05 \\
\hline Juntos por el Perú & 710.462 & 4,8 \\
\hline PPC & 590,378 & 3.99 \\
\hline Democracia Directa & 543,956 & 3.68 \\
\hline Perú Libre & 502,898 & 3,40 \\
\hline APRA & 402,330 & 2,72 \\
\hline Avanza País & 373,113 & 2,52 \\
\hline Perú Patria Segura & 350,121 & 2,37 \\
\hline Vamos Perú & 311,413 & 2,10 \\
\hline Renacimiento Unido & 265,564 & 1,79 \\
\hline Solidaridad Nacional & 221,123 & 1,49 \\
\hline Perú Nación & 206,128 & 1,39 \\
\hline Contigo & 158,120 & 1,07 \\
\hline
\end{tabular}

Fuente: ONPE- JNE (2020) Resultados oficiales, febrero. Tabla elaborada por el autor. 
Tabla 3

Votación en Lima y votos preferenciales

\begin{tabular}{|c|c|c|c|c|}
\hline PARTIDO & TOTAL & $\%$ & 1 & 2 \\
\hline Podemos Perú & 834,790 & $15.534 \%$ & 588,763 & 110,790 \\
\hline Partido Morado & 602,992 & $11.221 \%$ & 96,422 & 49,131 \\
\hline Frepap & 528,332 & $9.831 \%$ & 54,509 & 40,650 \\
\hline Acción Popular & 498,434 & $9.275 \%$ & 91,656 & 67,069 \\
\hline Fuerza Popular & 433,444 & $8.066 \%$ & 181,640 & 78,912 \\
\hline Frente Amplio & 306,835 & $5.710 \%$ & 123,926 & 50,606 \\
\hline PPC & 289,407 & $5.385 \%$ & 141,845 & 36,649 \\
\hline Juntos por el Perú & 264,162 & $4.916 \%$ & 36,649 & 26,144 \\
\hline Somos Perú & 253,529 & $4.718 \%$ & 53,644 & 14,555 \\
\hline Alianza para el Progreso & 187,895 & $3.496 \%$ & 24,610 & 18,098 \\
\hline Unión por el Perú & 180,435 & $3.358 \%$ & 31,652 & 33,251 \\
\hline Perú Patria Segura & 172,287 & $3.206 \%$ & 30,031 & 78,114 \\
\hline APRA & 137,472 & $2.558 \%$ & 64,986 & 30,694 \\
\hline Democracia Directa & 115,196 & $2.144 \%$ & 27,631 & 15,867 \\
\hline Avanza País & 111,698 & $2.079 \%$ & 45,610 & 6,799 \\
\hline Perú Libre & 111,011 & $2.066 \%$ & 17,282 & 13,730 \\
\hline Solidaridad Nacional & 84,128 & $1.565 \%$ & 20,585 & 9,489 \\
\hline Perú Nación & 82,125 & $1.528 \%$ & 21,880 & 7,191 \\
\hline Vamos Perú & 71,304 & $1.327 \%$ & 11,479 & 5,799 \\
\hline Contigo & 55,773 & $1.038 \%$ & 10,549 & 6,241 \\
\hline Renacimiento Unido & 52,669 & $0.980 \%$ & 6,799 & 3,952 \\
\hline Total de votos válidos & $5,373,918$ & $100.000 \%$ & & \\
\hline
\end{tabular}

Fuente: ONPE- JNE (2020) Resultados oficiales, febrero. Tabla elaborada por el autor.

Como se observa en la Tabla 4, esta encuesta decía que AP, APP, Partido Morado, Fuerza Popular, Somos Perú, Frente Amplio ocuparíamos los primeros lugares en ese orden, pero esto no se cumplió ni en ese orden ni con esos porcentajes. En el caso del Apra le ponía mayor porcentaje e igual al PPC, lo que no se cumplió; y lo más lejano de la realidad es el porcentaje muy abultado de AP en Lima que se diferencia en más de diez puntos (compárese tablas 3 y 4), cuando este fue más alto en provincias. Pero lo más desacertado fue que a Podemos le ponía 3,8 y al Frepap 3,4. Tampoco se cumplieron datos de Lima y de interior del país. En un último simulacro del 16 de enero (Datum, 2020) Frepap estaba $7^{\circ}$. con 3\%; en una encuesta 4 días antes de votar estaba $10^{\circ}$. Con $3.4 \%$; el simulacro final un día antes puso a UPP $7^{\circ}$. con $6.2 \%$. Es un temor a lo desconocido, a algo que se ha menospreciado (Ballón, 2020), desinterés y discriminación en los medios (Ráez, 2020), más siendo religión de sectores populares, un credo de los conos, ya Franco 
(1979) decía que la plebe urbana hasta crea sus propios santos; pero también poder y fanatismo son un peligro, el buscar que todos vistan y piensen igual, tener vocación de trabajo, organización, disciplina sobrehumana, es también propia de las sectas (Robles, 2020). Es un mecanismo de negación y autoengaño lo que sucedió. Pero esa imagen de gente trabajadora, humilde y marginada, no es para sacralizarlos, hemos visto actitudes machistas y homofóbicas, pero presencia femenina, son teocráticos y ultraconservadores; tampoco es para satanizarlos pues tienen propuestas para la agricultura, que poco importa a otros, es una construcción social como grupo religioso (Ballón, 2020), están por eliminación inmediata de inmunidad parlamentaria, investigación agraria, ética en los colegios, libre desafiliación de AFP, reforma de elecciones con reporte de gastos, transparentar contrataciones del Estado. En el caso de Urresti, tampoco se vio esta tendencia, así Ipsos un día antes de elecciones ponía a Podemos como $4^{\circ}$., con 5.1\%, Frepap y UPP presentaban $6.2 \%$ y $5.4 \%$. Y si bien Torres (2020) de Ipsos explica treparon por bajar el voto blanco, nulo y viciado, fue de últimas horas; esto no convence.

\section{Tabla 4}

Encuesta CPI sobre intención de voto elecciones congresales 2020 urbano y rural (voto válido)

\begin{tabular}{lccc}
\hline OPCIÓN DE VOTO & Total País & Lima Callao & Interior País \\
\hline Acción Popular & 15,0 & 20,3 & 12,6 \\
Alianza para el Progreso & 11,8 & 6,6 & 14,3 \\
Partido Morado & 10,4 & 14,6 & 8,4 \\
Fuerza Popular & 9,6 & 14,2 & 7,4 \\
Somos Perú & 6,8 & 6,4 & 6,9 \\
Frente Amplio & 5,7 & 4,4 & 6,3 \\
Unión por el Perú & 5,2 & 1,6 & 6,9 \\
APRA & 4,0 & 3,2 & 4,4 \\
Podemos Perú & 3,8 & 6,2 & 2,6 \\
Frepap & 3,4 & 3,4 & 3,4 \\
PPC & 3.3 & 4,1 & 2,9 \\
Otros partidos & 21,0 & 15,0 & 23,9 \\
\hline
\end{tabular}

Fuente: CPI (2020) 4.044 encuestados del 15-27 enero 2020. Tabla elaborada por el autor.

A Urresti se le asocia a violencia contra delincuentes y venezolanos. Y Antauro a fusilamientos a corruptos y desviados, expulsar venezolanos, Fuerzas Armadas en las calles para luchar contra el crimen y la inseguridad (Zambrano, 2020). Y Chávez en FP es mano dura y negadora de realidad. Sucede que muchos peruanos están por la mano dura, son homofóbicos y xenofóbicos o racistas; y no es cierto que si la izquierda iba unida ganaba más congresistas, el FA concedió y provocó que Juntos se quedara con los pasivos y estigmas, no es un voto utópico, ni de rebeldía, no achorado (Robles, 2020). 
Como podemos ver en la Tabla 5, los 3 resultados difieren, lo cual significa que las encuestadoras no acertaron tampoco en estos niveles. Ellas señalaron puntajes fueron más altos para AP y APP, siendo más bajos para Podemos y Frepap, fueron ligeramente más altos para el APRA y Juntos, siendo más altos en boca de urna para Partido Morado. Y en conteo rápido el porcentaje fue ligeramente más alto para UPP. Por tanto, el mayor error se dio con Podemos y Frepap en ambos casos y con diferentes porcentajes menores al resultado oficial. Gamarra (2020) dice: "los medios de comunicación y encuestadoras creen que pueden y deben manipular la opinión pública y al electorado, por eso tuercen sus resultados en el sentido que les interesa influir y promover y creen ilusamente que la gente lo seguirá", como se ve una vez más no les hicieron caso, es demás.

\section{Tabla 5}

Resultado IPSOS sobre votos válidos para canal 4 tv sobre boca de urna y conteo rápido elecciones congresales 2020 comparado con el resultado oficial

\begin{tabular}{lccc}
\hline OPCIÓN DE VOTO & Boca de Urna \% & Conteo Rápido \% & Res. Oficial \% \\
\hline Acción Popular & 11,8 & 10,1 & 10,26 \\
Podemos Perú & 7,4 & 8,2 & 8,38 \\
Frepap & 7,0 & 8,8 & 8,38 \\
Alianza para el Progreso & 8,8 & 8,0 & 7,96 \\
Partido Morado & 8,1 & 7,7 & 7,40 \\
Fuerza Popular & 7,1 & 6,9 & 7,31 \\
Unión por el Perú & 6,2 & 6,9 & 6,77 \\
Frente Amplio & 6,2 & 6,1 & 6,16 \\
Somos Perú & 7,0 & 5.6 & 6,05 \\
Juntos por el Perú & 5,0 & 5,1 & 4,80 \\
PPC & 3,4 & 4,0 & 3,99 \\
Democracia Directa & 4,0 & 4,1 & 3,68 \\
Perú Libre & 3,3 & 3,5 & 3,40 \\
APRA & 2,8 & 2,6 & 2,72 \\
Avanza País & 2,4 & 2,5 & 2,52 \\
Perú Patria Segura & 2,2 & 2,4 & 2,37 \\
Vamos Perú & 2,3 & 2,0 & 2,10 \\
Renacimiento Unido & 1,3 & 1,6 & 1,79 \\
Solidaridad Nacional & 1,4 & 1,4 & 1,49 \\
Perú Nación & 1,4 & 1,4 & 1,39 \\
Contigo & 0,9 & 1,1 & 1,07 \\
\hline
\end{tabular}

Fuente: Resultados Boca de urna y Conteo Rápido América TV 4- IPSOS, ONPE- JNE (2020). Resultados oficiales, Tabla elaborada por el autor.

Latina TV 2 anunció días antes y el mismo día daría resultados a boca de urna y conteo rápido pero no aparecieron sino por lo menos 3 horas después. Se notó cierto desconcierto con lo sucedido y no se sabe si hubo duda en presentar 
los resultados, pero por diferencias se ve era por la votación de Podemos, UPP y FREPAP.

\section{DISCUSIÓN DE RESULTADOS}

Vemos una alta participación ciudadana en la votación, no se llegó a dar tampoco un alto porcentaje de votos blancos como señalaban las encuestadoras, y los votos nulos fueron en un 7.09\%, es posible que haya habido una decisión tardía al decidir, y esta se canalizó sobre todo hacia UPP y Podemos, sin embargo no puedo darse una opción tan grande por estos partidos, por ello pese a que la campaña por el no voto en blanco porque favorecía a partidos opositores a Vizcarra parece tuvo éxito, se canalizó hacia diversos partidos; más bien las encuestadoras no registraron estas tendencias que se venían dando. En su página Montero (2020) antes de las elecciones señaló cuáles eran los partidos que tendrían congresistas, señaló Juntos estaría muy cerca de alcanzar la valla e indicó que sin embargo habría dos sorpresas pero que no las tenía precisas (esas eran UPP y Podemos) y no solo indicó que no las visualizaba claramente, sino que indicó su limitación de no haber podido salir de Lima para poder tener un panorama completo.

Igualmente, podríamos decir que tuvo éxito la campaña contra el Partido Morado y esto también fue señalado por el autor diciendo se venía una avalancha de votos para ese partido y por eso sobre todo los opositores a Vizcarra buscaron una noticia que detuviera ese avance pues consideraban ellos eran "vizcarristas", al final fueron una noticia sobre Guzmán y otra de Mora. Que si salieron a último momento, no es lo relevante, sino que nuestros políticos acostumbrados están a este tipo de guerras psicológicas para destruir al rival, ninguno es víctima.

Y era patético escuchar a políticos machistas, violentos, infieles, etc, hablando de moral, defensa de la mujer, fidelidad, típicos ejemplos de formación reactiva.

Y Nuevo Perú partido central de Juntos, tomó pésimas decisiones a intentar unirse a un personaje sentenciado, machista, homofóbico, alejó incluso a algunos de sus líderes. Pretenden así algunos presentar a la izquierda como tener el patrimonio de la moralidad? No es raro, en nuestro país escuchar incluso a intelectuales o psicólogos hablar de igualdad y actuar de manera racista y discriminatoria, de hablar de moralidad y hacer actos inmorales en sus actuaciones, discriminar a sus rivales, perjudicarlos con toda injusticia y luego juzgar la corrupción judicial; criticar a Fujimori u otros políticos y ser autoritarios y despreciativos; o peor aún criticar a Fujimori y no ser nada trabajadores, defecto que no tenía Fujimori pues era trabajador. El problema no es Keiko, ni Fujimori, en estas elecciones ya son minoría, el problema de algunos partidos son ellos mismos, el problema es cantidad de señoras K, señores G, Antauros, Urrestis y mesiánicos. Vizcarra es parte del gobierno de PPK que mostró para nada era alternativa a los problemas del Perú y menos para los sectores más pobres o mayoritarios, perderse en probar que no 
tiene capacidad, visión, en culparlo y responsabilizarlo de todo es absurdo. Vizcarra no es el problema, igual se diría que el problema es que hay muchos Vizcarras, personas que se destruyen o complican solos, con estas elecciones ya no está el fujiaprismo, veremos ahora si Vizcarra gobierna bien. En verdad, lo que vemos es un mecanismo de proyección en la clase política, ven enemigos cuando el enemigo está dentro de ellos mismos. Qué autoridad o político ha dado una alternativa ante la tragedia de Villa El Salvador cuando un camión de gas explotó?, no pueden decir el otro es el responsable.

En Perú está es típica la disonancia cognitiva en todos los espacios, esa incongruencia interna del sistema de ideas, creencias y emociones (cogniciones) que percibe una persona que tiene al mismo tiempo dos pensamientos que están en conflicto, o por un comportamiento que entra en conflicto con sus creencias (Festinger, 1962). Pero es comprensible la gente intente reducir incongruencias; pero el problema es que predica un modelo, unos valores y luego no los han cumplido ni los cumple; o se quiera controlar a los demás lo que deben hacer; se haga promesas creando falsa expectativa; decir cosas falsas; se falsee emociones; se simule coincidencia o amistad y se lo ataca; dar una imagen falsa. Y esto es más bien incoherencia, manipulación, mendacidad, inconsecuencia, hipocresía, traición, farsa. Por eso ya no crece la desconfianza y desesperanza.

Es común se digan socialista, cristiano, humanista, creyentes, ateos, etc., y hagan lo contrario, que se priorice intereses creados sobre todo crematísticos, afán de cargos, vanidades, etc. No es eso disociación? Quizá locura, por qué el elector y no la clase política debe ser juzgada?

Fue curioso ver salir a todos los partidos en televisión diciendo que habían ganado, en especial AP, pero en verdad no ganó nada pues su votación solo era $1.88 \%$ mayor que la de Podemos y el Frepap y la diferencia porcentual entre bancadas es mínima, pues entre AP que quedó primero y FA que quedó séptimo hay apenas algo más de 5\%. Incluso FP dijo fue un éxito pese a su contundente derrota porque de 73 congresistas ha pasado a tener 15. Solo Ibañez del Apra hizo una autocrítica. AP sacó muy bajo porcentaje pero por ocupar el primer lugar obtuvo 25 escaños y APP que le sigue 22. Sin embargo, están obligados a dialogar ya no imponer.

Es claro que la votación Podemos es de Lima, e igual del Partido Morado, la de Fuerza Popular, de Acción Popular pero muy disminuida, la del PPC que en gran porcentaje es por Beingolea. La votación de UPP y Frente Amplio es de provincias sobre todo de la sierra centro, la de Juntos es de Lima, lo que significa que los votos de este último migraron hacia posiciones más radicales como UPP y al Frente Amplio. APP y Somos obtuvieron votos sobre todo del interior del país. En el norte solo Piura mantuvo votación para FP. 
En votaciones preferenciales, vemos que Urresti con su primer lugar lo posiciona como buen candidato presidencial, dependiendo de su actuación en el Congreso y de avanzar más en provincias. De Belaunde muestra ser buen candidato para acompañar la lista de Partido Morado u otro, e igual sucede con Gino Costa; se puede ver que lo sucedido con Guzmán y Mora restó muchos votos a su partido, por lo que su chance es muy limitada. Martha Chávez podría ser la candidata de FP aunque sus posibilidades son muy remotas incluso con Keiko, presentado como populismo de derecha, queda en su núcleo duro. Igual Antauro Humala ya comprobó sus reales posibilidades no de ganar pero sí de posicionarse y ha logrado poner a su entorno más íntimo en el Congreso (Chaparro, 2020), no es un candidato real, no tiene opción de ganar (Torres, 2020). Arbizu y Sánchez se muestran como buenos candidatos a congresistas en Juntos para las próximas elecciones, pero tendría que recuperar aunque sea en algo su votación nacional. Beingolea tiene algunas simpatías pero sin chance para las presidenciales. Se pudo comprobar que Cilloniz y Reggiardo no son buenos candidatos para Presidente. Las posibilidades de Solidaridad Nacional son nulas y puede empeorar su votación, más ahora que Castañeda está preso y Luna enjuiciado. Somos pese a su buena votación, no tiene candidatos presidenciables y pierde votación en Lima. APP tiene buena votación y congresistas pero Acuña como presidenciable tendría que avanzar mucho, además los juicios y acusaciones abundan además burlas a Acuña.

Así en el Congreso ahora tenemos un fujimorismo antifujimorista (Urresti), un populismo fujimorista religioso (Frepap), un fascismo antisistema (Antauro Humala), un centro sin rumbo con varios líderes antilíderes sin carisma; y un fujimorismo sin líder carismático; una izquierda sin masas, si fe, sin mitos, sin vocación por el poder, tanto o más golpeada por el rechazo popular que los opositores al cierre del Congreso y defensores de la corrupción. El síndrome de Procusto que tipifica a aquellos que, al verse superados por el talento de otros, deciden menospreciarlos; incluso deshacerse de ellos; el miedo los lleva a vivir en una continua mediocridad, donde no avanzan ni dejan que otros lo hagan, está presente en toda la clase política y no es exclusivo de la izquierda. El Apra el paradójicamente, es hoy un aprofujimorismo antiaprista, donde no solo no hay hayismo, sino no está Haya y que ni siquiera puede invocar a Alan García pues este es rechazado por el pueblo. Y se podría decir que este voto por Podemos y UPP es loco, delirante, absurdo, ignorante; pero los defensores de la corrupción y contra las elecciones congresales estaban candidateando; cómo los destructores del congreso iban a fortalecerlo, y los no elegidos eran los número uno en la lista. Cómo podrían hablar de golpe de estado si ni el TC les dio la razón y lo que ellos hacían en el Congreso era un permanente golpe de Estado. Y recibían enormes donaciones de empresas diversas con el fin de ser protegidas y cómo ellos iban a cambiar el Congreso, cómo una candidata con denuncia de antecedentes de trastornos mentales iba a ofrecerse como alternativa, ¿puede haber algo más disociado de la realidad y más delirante?, la clase política que habla de 
ética y moral que se les ve tener tantos actos inmorales puede ser creíble? Quién no se daría cuenta que esto es una formación reactiva? Es menos loco creerles al Frepap que a esa clase política repudiada? ¿Cómo tantos absurdos pueden cuestionar "absurdos populares"? Qué grupo político podría hablar de ética cuando todos los principales líderes están en la cárcel o enjuiciados? Villarán, Santos, Toledo, Keiko, Humala, Castañeda, PPK. El detenido izquierdista Santos que dijo "que la izquierda no existe en Perú" o Cerrón con sus mensajes machistas podrían dar lecciones de moral. Quizá AP un partido conservador, que representa a los gamonales tradicionales, al pasado superado, su colusión con el fujimorismo (Robles, 2020), con un Diez Canseco que tuvo que dejar la vicepresidencia y cuyos varios de sus locales KFC tienen problemas? O quizá puede haber algo más insufrible que la soberbia y oportunismo de Barnechea? O Somos Perú, cuyo líder cabeza Espinoza tiene acusación de maltratador y 51 procesos penales? O el casi santo Frepap con Cayllahua con denuncia de violencia física familiar? O podríamos decir quién tiene la verdad en los líos internos del Frepap? Cuando esta es una pugna de 20 años. Y Antauro? Pues no hay tal radicalidad, está en una aventura electoral, pragmatismo que le rinde frutos, el mismo lo dice "transformar la máquina de guerra en una máquina electoral". Y aunque parezca paradójico, Guzmán y Antauro se parecen en liderazgo, obsesión, deseos, afán de ser Presidentes pero sus rutas son distintas: zona sur y Lima. Antauro no ha superado ni a Ollanta ni a Verónika. Guzmán llega a los de mayores ingresos y al resto llega Urresti, Morado solo repite a Lourdes y a PPK. Así Antauro luego de ver su éxito se involucra en elecciones, quiere ser un líder nuevo pero recorre el camino de su hermano que "desprecia". Morado partido que quiere ser nuevo pero escoja el camino recorrido por la derecha limeña. El Perú pese a los nuevos actores sigue en el mismo escenario (León, 2020). Además, Antauro es un movimiento extremista y xenófobo. Ahora, tenemos un Congreso de caudillos etnicistas, racistas, populistas, de mano dura, y Frepap homofóbico (Zambrano, 2020). Como en el escenario de 1990 donde pobreza, violencia terrorista y desesperanza hicieron surgir a Fujimori como antisistema y por ello fue elegido. Así, Chaparro (2020) dice hay un sentimiento de desafección y antisistema,frente al caos privilegian la verticalidad como solución; y algunos que añoran a Fujimori optaron por Frepap como ordenamiento moral. Y es que Fujimori es la imagen más articulada del antisistema. El Frepap es fenómeno de coyuntura. El voto de protesta lo canaliza Podemos, UPP y Frepap ante la desilusión ante Keiko. El antisistema se da cuando hay identidades partidarias negativas masificadas: Urresti y Antauro. Dargent (2020) coincide y dice es un voto de rechazo a la política, es protesta escondida. Torres (2020) dice Urresti tiene arrastre propio pero le falta llegar a todo Perú y Antauro representa el sur del país. Meléndez (2020): "la informalidad se expresa electoralmente vía populismos mano dura, nacionalismos fascistoides y marginalidad religiosa. 
De la Puente (2020) plantea que los resultados electorales son un débil impulso a la transición y a la innovación del sistema político; exponen una democracia mínima, el "sistema" ha ganado, no hay interrupción. La dispersión, y el vacío son los principales elementos, faltan mensajes diferenciadores; el vacío por dispersión amenaza la democracia peruana. Falsa la supuesta radicalización de los electores, se ha castigado lo conservador. Hay límites de la élite política limeña para relacionarse con las regiones. Las votaciones del Frepap, Podemos y UPP son una insurgencia anónima. Esta emergencia no es un fenómeno estructural, no tanto radicalismo sino desafección, un "anti". Ciertos análisis son reacciones dramáticas: culpa de "no los vimos venir", obviando el factor de volatilidad; y contemplativa ante Frepap.

Estoy de acuerdo con De la Puente, sé de su seriedad y calidad. Estas actitudes señaladas en anterior estudio (Montero, 2019) se combinan la actitud de "no saber por quién votar porque todos parecen iguales". Se diría que hay hasta actitudes racistas y discriminativas con Frepap, donde se dice lo analicen antropólogos y son vistos como raros, incivilizados. Pero este resultado es producto de que recorren el país hace 51 años, de participar en diversos procesos electores, un sostenido trabajo partidario y canalizaron el descontento popular (Zambrano, 2020 b), producto de un trabajo de base que los partidos debieran imitar, sus movilizaciones de campesinos sin tierra y migrantes pobres vienen del 68 (Ráez, 2020); empatan con el sentido común, es mesiánico y milenarista y depende de lo que haga para su éxito (Ballón, 2020).

Lauer (2020) señala "el actual Congreso se moverá bajo la constante obligación psicológica de ser "mejor que el anterior", un factor subjetivo", lo psicológico podría ser definitorio tal vez.

Respecto al APRA, Montero $(1979,2020)$ indicó que su crisis se venía gestando hace tiempo. Pero ahora por primera vez desde 1932 no tiene congresistas. En 1985, García obtiene el 53\% de votos válidos y Barrantes 21\%, de 60 senadores el APRA tuvo 32 y de 180 diputados tuvo 106 (Nohlen,1978). En 2006 APRA tuvo 36 congresistas, 2011 solo 4 y en 2016 en alianza con PPC 5. Tiene 2 bandos y rechazo de un gran sector a la dirigencia, pérdida de contactos populares, han perdido identidad, (Briceño, 2020). Se busca defender la memoria de García pero Roca (2020) dice no es lo mismo defender la memoria de Haya de la Torre y la de García", hay corrupción y están desideologizados y no se sabe entre los militantes su orientación, se dice es de centro o centro izquierda, "no somos un partido de izquierda democrática" e indica en 2018 Alan le dijo "Mi discurso ya no pega. El drama es que la gente no me cree". Carla García hija de Alan dijo que podría ser congresista "en favor de los pobres del Perú" (Leiva, 2020) y Mulder dijo podría ser buena candidata, lo cual muestra cuán fuera de la realidad están líderes como él en el Apra; es una formación reactiva. 
Frente a las imágenes de corrupción de la clase política y a la desesperanza que esto crea, no es raro que con Frepap haya "jugado a su favor la imagen de honradez asociada a su condición religiosa, así como el deseo de bastante gente de ensayar nuevas alternativas, dado el desencanto general con relación a los políticos" (Manrique, 2020).

\section{CONCLUSIONES}

Estas elecciones congresales han sido un avance en el rechazo a los partidos y políticos defensores de la corrupción, pues han sido derrotados y el número de congresistas de partidos como Fuerza Popular se ha reducido y el Apra no alcanzó la valla; pero igualmente hubo un rechazo a todos los personajes en contra del cierre del Congreso pues no alcanzaron la valla y su votación fue ridícula. Los electores quisieron protestar pero no con voto blanco ni viciado.

La sorpresa ante el resultado, muestra cuán poco conocemos nuestra realidad, cómo no sabemos del trabajo de organización y de actualización ideológico partidaria (Manrique, 2020).

Tenemos un Congreso fragmentado, pero esto podría obligar al diálogo. Los efectos sobre las próximas presidenciales dependerá de "cómo se conduzcan los partidos que han logrado victorias intempestivas; pueden surgir algunos liderazgos nuevos y hundirse otros, ambas cosas capaces de cambiar la topografía política" (Lauer, 2020).

Estos resultados es en general son un fuerte cuestionamiento a la clase política, es pues una votación antisistema. Esto se da sobre todo en el sur del Perú, y en general en el país con Frepap, sin embargo con Podemos su mayor votación fue en Lima y se debe sobre todo a la figura de Urresti. Se ve el apoyo a AP ha disminuido en Lima y APP sobre todo tiene fuerza en interior del país. Ahora, si bien UPP ha conseguido buena votación no es un peligro para las presidenciales, es evidente que no ganaría unas elecciones. Pero el voto por AP es un sí al sistema e igual más moderado con el Partido Morado. El sistema fue cuestionado pero ha resultado ganador y se afirmó. Pero los actores actuales no serán al parecer determinantes en las próximas elecciones presidenciales 2021. Es posible nuevos actores puedan tener mejor votación, como Forsyth o Del Solar, los tradicionales no tienen posibilidad presidencial.

Como señala De Echade (2020) hay varios procesos democráticos avanzando. El cambio de la Constitución es urgente porque es producto de una dictadura, no altura del Bicentenario.

\section{Agradecimientos / Acknowledgments:}

A los miembros del IIPSI y Comité Editorial de su revista de Investigación por aceptar esta propuesta para evaluarla y aceptar su publicación 


\section{Fuentes de financiamiento / Funding:}

El presente estudio es autofinanciado.

\section{Rol de los autores / Authors Roles:}

El autor realizó las diversas fases de la investigación.

\section{Aspectos éticos / legales; Ethics / legals:}

El autor declara no haber incurrido en aspectos antiéticos respetando los códigos de investigación con humanos (Código de Ética del Colegio de Psicólogos del Perú).

\section{Conflicto de intereses / Competing interests:}

El autor manifiesta no haber tenido ningún conflicto de intereses al realizar esta investigación y artículo.

\section{REFERENCIAS}

América TV 4- IPSOS (2020). Boca de urna, Lima, 26 enero.

América TV 4- IPSOS (2020). Conteo rápido, Lima, 26 enero.

Ballón (2020). Entrevista. Lima: Hildebrandt en sus trece No.447 pp.4-5.

Briceño, A. (2020).El drama del Apra. Hildebrandt en sus trece No.447 pp.6-7.

CPI (2020). Elecciones congresales extraordinarias 2020, Perú Urbano y Rural. Intención de voto según partidos políticos 15-27 enero 2020.

Chaparro, H. (2020). Entrevista. Lima: Hildebrandt en sus trece No.447 pp.10-11.

Dargent, E. (20Li20). Entrevista. Lima: Hildebrandt en sus trece No.447 pp.10-11.

Datum (2020). Simulacro de voto a Elecciones Congresales 2020. Lima, 16 de enero

De Echave, J. (2020). Será un largo año y todo puede cambiar. Lima: Hildebrandt en sus 13 No.447 pp.16.

De la Puente, (2020). Pescados y mariscos. Diario La República, 31 enero.

Festinger, L. (1975). Teoría de la disonancia cognitiva. Madrid: Instituto de Estudios Políticos.

Gamarra, R. (2020). Encuestadoras quedaron como la mona. Lima: Hildebrandt en sus trece No.447 pp.26

García, C. (2020). Entrevista con Milagros Leiva. Willax TV, 20 enero.

Hernández, Z. (2020). Conciencia social, alternancia y primeros escaños para mujeres en el Congreso de la República 2020. Lima: Mujer y Sociedad.

Hildebrandt, C. (2020). Elecciones y regreso a la cárcel. Lima: Hildebrandt en sus trece No.447 pp. 12 
Ipsos (2020). Composición del Congreso. Proyección según cifra repartidora, 25 enero.

Lauer, M. (2020). Sorpresas que no sorprenden. Diario La República, 3 febrero.

Lazarsfeld, Berelson y Gaudet (1962). El pueblo elige. Cómo decide el pueblo en una campaña electoral. Buenos Aires: Ediciones 3.

León, C. (2020). Aunque no lo parezca, el mismo escenario. Lima: Hildebrandt en sus trece No.447 pp.29

Manrique,N. (2020). Nuevo mapa político del Perú. Diario La República, 28 enero.

Montero, V. (2019 a). La adicción al poder y la soledad del poderoso. Descifrando aspectos ideológicos y psicosociales que traban la convivencia humana en el Perú. Revista De Investigación En Psicología, 22(1), 157-176. Recuperado 31 jul. 2019. https://revistasinvestigacion.unmsm.edu.pe/index.php/psico/article/view/16588 DOI: https://doi. org/10.15381/rinvp.v22i1.

Montero, V. (2019 b). Análisis de actitudes de universitarios sobre líderes políticos, instituciones, autoridades, valores, el Perú y personajes históricos. Revista De Investigación En Psicología, 22(1), 3-28. Recuperado 31 jul. 2019. https://revistasinvestigacion.unmsm.edu.pe/index.php/psico/article/view/16578 DOI: https://doi. org/10.15381/rinvp.v22i1.16578

Montero, V. (2020 a). Decodificando aspectos psicosociales e ideológicos en la búsqueda de la verdad objetiva y la verdad jurídica. Revista De Investigación En Psicología, 22(2), 379-394. Recuperado 2 febrero 2020. https://revistasinvestigacion.unmsm. edu.pe/index.php/psico/article/view/17436 DOI: https://doi.org/10.15381/rinvp. v22i2.17436

Montero, V. (1979, 2020 b). Psicología de masas del aprismo. Lima: UNMSM. $2^{\text {a }}$ Edición en preparación.

Nohlen, D. (1978). Sistemas electorales en el mundo. Alemania: University of Heidelberg.

ONPE (2020) Resultados oficiales, febrero. https://www.onpe.gob.pe/

Ráez, C. (2020). Entrevista. Lima: Hildebrandt en sus trece No.447 pp.4-5.

Robles, J. (2020). Horrible oye. Lima: Hildebrandt en sus trece No.447 pp.15.

Roca (2020). Entrevista. Lima: Hildebrandt en sus trece No.447 pp.6-7.

Sánchez H. (2016). Tipos y Métodos de investigación. Lima: Universidad Ricardo Palma. https://issuu.com/luispiedra/docs/sesion_12_-_tipos_y_m_todos_de_inv

Torres, A. (2020). Entrevista. Lima: Hildebrandt en sus trece No.447 pp.10-11.

Zambrano (2020). Peces gordos. Lima: Hildebrandt en sus trece No.447 pp. 4,5.

Zambrano (2020). Apuesta de riesgo. Lima: Hildebrandt en sus trece No.447, pp.9-11. 